Sanja Runtić, Josip Juraj Strossmayer University in Osijek, Croatia - Jasna Poljak Rehlicki, Josip Juraj Strossmayer University of Osijek, Croatia

\title{
Varalica uzvraća pogled: rekonceptualizacija drugog u djelima suvremenog indijanskog umjetnika Jamesa Lune
}

\section{Abstract: The Trickster Returns the Gaze: Reconceptualizing the Other in the Work of Contemporary Native American Artist}

\section{James Luna}

The paper analyzes the use of humor in the work of Luiseno artist James Luna. Utilizing the media of performance, photography and installation, using himself as the object of representation, Luna has created a recognizable artistic style that addresses the complex issues of American Indian identity and representation. His installations The End of the Frail (1990-91) and The Artifact Piece $(1987,1990)$ both point at the constructed nature of Native identity. Whereas the former employs satire, self-stereotyping, parody and humor to expose and confront the colonial myths, distorted attitudes and pictographic representations of Native Americans, the latter addresses the issues of Native absence and invisibility in the dominant culture. Representing himself as an artifact to provoke laughter, shock and discomfort, in The Artifact Piece Luna clearly disclosed the relationship between Western institutions of knowledge and the culture of the spectacle. Both installations draw attention to the tie between imperialism and material forms of production and representation, indicating the still ongoing institutional investment in Native allegorization through commodification and scientific practices, the fact that even today Native American identity is compromised by the colonial discourse and its disciplinary practices and imagination. Using Bhabha's concepts of mimicry and hybridity, Bakhtin's theory of humor and Vizenor's trickster holotrope, our analysis discusses the subversive potential of Luna's auto-ethnographic project, its 
potential to deconstruct the meta-narratives of Otherness and colonization, and create new spaces for social dialogue and cultural survival.

Keywords: James Luna, mimicry, Bakhtin, humor, Vizenor, trickster, decolonization

Premda se na prvi pogled možda tako ne čini, val autohtone indijanske književnosti i umjetnosti, čiji se razvoj razabire unazad nekoliko desetljeća, ni po čemu ne podilazi romantičnoj fascinaciji Zapada domorodačkim kulturama i trendovskom new age zanimanju za njihovu tradiciju i duhovnost. Naprotiv, djela ovih pisaca i umjetnika odišu polemičkom težnjom za samoodređenjem i suverenitetom te potrebom da na autentičan i nov način progovore o povijesnom i suvremenom iskustvu američkih Indijanaca, ali i o njihovoj još uvijek prisutnoj marginalizaciji u dominantnoj kulturi. Jedan od istaknutih pripadnika ovog novog alternativnog pokreta na američkoj kulturnoj sceni, umjetnik iz naroda Luiseno James Luna, svojim brojnim instalacijama i performansima, namijenjenima isključivo zapadnoj publici, na osebujan i provokativan način ukazuje na indijansko iskustvo drugog, kao i na nužnost revizije pamćenja, popularnih predodžbi i stavova o američkim starosjediocima. Cilj je ovog rada uz pomoć Bhabhinih koncepata mimikrije, hibridnosti i trećeg prostora, Bahtinove teorije humora i Vizenorova holotropa varalice ukazati na subverzivan i antikolonijalni karakter autoetnografskog izričaja ovog suvremenog starosjedilačkog umjetnika. Koncept Indijanaca kao drugih star je koliko i kolonizacija njihova kontinenta. Čak i danas, pet stoljeća kasnije, čini se kako pogrešnim predodžbama o američkim domorocima nema kraja. Jedno je od glavnih proturječja kolonijalnog projekta njegova utemeljenost kako na iščeznuću d rugog (cf. Pease 29) tako i na njegovu postojanju. Zaposjevši ne samo geografski prostor nego i "konstruirani prostor domorodačkog drugog" (Owens, 2001: 16), kolonizator pokušava istodobno "civilizirati" druge i zatočiti ih u "vječitu drugost" (Loomba 176). Kao rezultat, od svojih početaka dominantne su predodžbe indijanski identitet odredile kroz dvije krajnosti - trop brutalnog ratnika koji se opire civilizaciji i romantični stereotip "plemenitog divljaka" (cf. Bevis 593; Horsman 104; Allen 4-5), "bijelog Indijanca", šutljivog prijateljskog indijanskog sluge (cf. Deloria 200) koji, uvjeren u superiornost doseljeničke kulture, pristaje biti kolateralnom žrtvom njezina civilizacijskog napretka. Bilo da se radi o primitivcima koji "vrebaju iz divljine", osvetoljubivim ratnicima koji napadaju pionirska kola, vjernim suputnicima, plemenitim junacima ili princezama (cf. Bataille 4, 5; Churchil 78), sve simboličke inačice Indijanca kao drugog dijele jedno obilježje - identitet koji 
označuju vezan je za prošlost, otrgnut od povijesnog procesa Zapada i zapadne pripovijesti o sebstvu. One, paradoksalno, daju život umirućoj rasi, "Indijancima koji, na ovaj ili onaj način, sudjeluju u procesu svog nestanka" (Owens, 1998: 82).

Alteritet nudi dva moguća stava prema drugomu - poistovjećenje i različitost, tumači JanMohamed. Dok poistovjećenje zanemaruje razlike i drugog procjenjuje s dominantne kulturalne pozicije, "različitost" podsjeća da je "drugi nepovratno različit", te da stoga ne može biti niti shvaćen niti prihvaćen (18). Prema Dorrisu, od svog su postanka alegorije indijanskog identiteta očitovale "dugotrajnu težnju europskih i euro-američkih mislilaca da Indijance smatraju toliko 'drugima', toliko fundamentalno i duboko različitima, da im uskraćuju neka obilježja čovječnosti” (101). U skladu s postmodernim gledištem Jeana Baudrillarda, koji popularni prikaz američkih Indijanaca smatra dokazom dominacije virtualnog nad zbiljskim u američkoj kulturi $(2,13-15)$, mnogi teoretičari indijanske kulture ističu kako su, među inim i umjetnost, književnost, znanost i mediji, stvorili "Indijanca koji nikad nije postojao" (Bataille 4-5), konstrukt, "statički artefakt", "mjesto označavanja" koje treba isprazniti i iznova ispuniti euro-američkom kulturom (Owens, 1998: 5, 22). "Indijanska" pripovijest nema ništa sa stvarnim živućim ljudima na koje se odnosi, tvrdi indijanski pisac i književni kritičar Louis Owens (1998: 45), citirajući Geralda Vizenora, jednog od najznačajnijih predstavnika suvremene indijanske kritičke teorije: "Svi smo mi izmišljeni kao Indijanci ... i zarobljeni smo u kovanicama i riječima poput artefakata" (cf. Owens, 1998: 5). Za Vizenora indijanac $^{[1]}$ je romantičan kolonijalni izum, odsustvo pravih domorodaca i njihove tradicije (1998: 14, 35, 37, 183-189; 1990: 279; Bataille 4), simulacija koja je postala glavnom krinkom kolonijalnog nadzora (Vizenor, 1994: 9; 1976 xiii). Taj nadzor još uvijek traje, upozorava Vizenor. U suvremenoj američkoj kulturi na djelu je rat riječi, tvrdi on, koji može biti poguban po opstanak domorodačkih kultura, ukoliko one ne budu kadre odijeliti se od dominantne retorike "indijanstva" i autoritarnog diskursa (1976: vii, viii). Identiteti nastaju iz "narativizacije sebstva", piše Stuart Hall: Identiteti se tiču pitanja korištenja izvora povijesti, jezika i kulture ... ne odnose se toliko na pitanje "tko smo" ili "odakle smo došli" koliko na to ... kako smo prikazani i na koji način to može utjecati na naš prikaz sebe samih. Identiteti se stoga stvaraju unutar, ne izvan prikaza. (4) 
Svjestan te činjenice, suvremeni indijanski umjetnik James Luna koristi medije performansa, multimedijalne instalacije i fotografije kako bi stvorio alternativu kolonijalnoj metapripovijesti, razotkrio i redefinirao stereotipe, pogrešne stavove i prikaze indijanskog identiteta u dominantnoj kulturi. Njegova instalacija Kraj slabašnoga (izv. The End of the Frail, 1990-91) nastala je kao odgovor na skulpturu Jamesa Earlea Frasera Kraj puta (izv. The End of the Trail) koja prikazuje indijanskog ratnika kako umoran stoji na rubu litice s kopljem u ruci, nekad ponosno podizanima u borbi i lovu, koje sada beživotno visi prema tlu. Tema i kompozicija Fraserove skulpture, nastale 1890-ih, na vrhuncu američko-indijanskih ratova, još i danas predstavljaju opće mjesto američke popularne imaginacije svojih starosjedilaca, koja je od devetnaestog stoljeća naovamo stvorila bezbroj sličnih vizualnih portreta Indijanca koji izumire.

Etnografske su predodžbe oduvijek fascinirale istraživače, koji su starosjedioce od samog početka zarobljavali u slike i rezbarije, tvrdi Vizenor (1998: 161-2). 


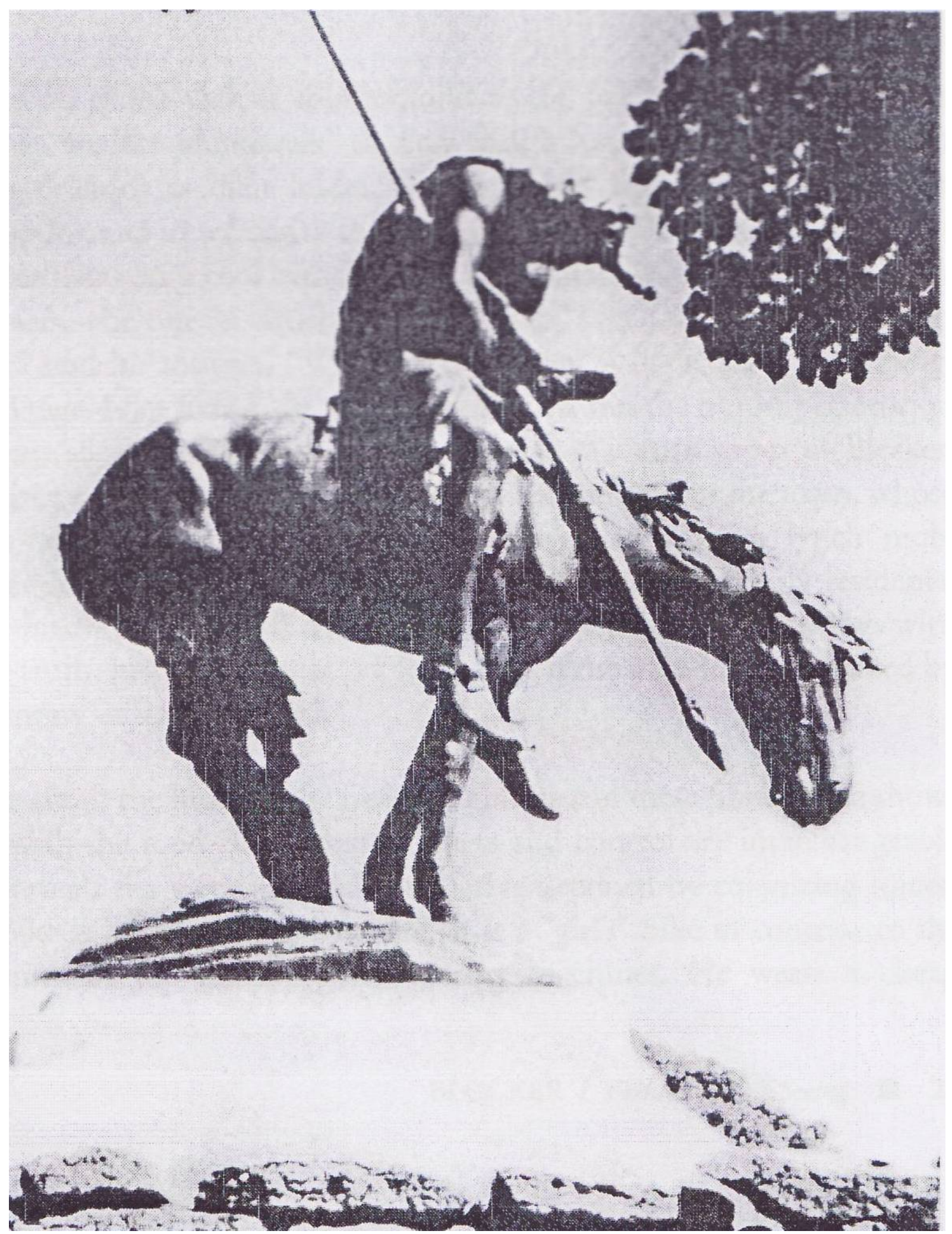

Figure 1: James Earle Fraser: The End of the Trail - 1894. (Fraser 26). [F2]

Prema Vizenoru, upravo je izum fotografije sredinom devetnaestog stoljeća odigrao veliku ulogu u distribuciji izmišljenog indijanstva u dominantnoj kulturi (1998: 152). Fotografije su važan adut u 
rukama kolonijalnih institucija, ističe Loomba (99). Slično, i hooks slike vidi moćnim instrumentom unutarnje kolonizacije koji u suvremenom svijetu igra ključnu ulogu u provođenju političke moći i konstruiranju odnosa među etničkim skupinama (1992: 5). I Anne McClintock ukazuje na blisku vezu imperijalizma i vizualnog prikaza. Zbog tehnološke usavršenosti pri repliciranju zbilje, slikovni je jezik povukao znak jednakosti između sebe i zapadnog znanja te tako prigrabio autoritet "da presloži hijerarhije svjetske povijesti”. U službi političkog prikazivanja, fotografija stoga svoj objekt izvlači iz povijesnog konteksta i uranja ga u panoptičko vrijeme koje obilježuje naraciju imperijalnog progresa (123-125). Možda jedan od najboljih primjera ovakve vizualne mitografije fotografski je projekt Edwarda S. Curtisa iz 1906. godine pod naslovom Sjevernoamerički Indijanac (The North American Indian). Samouki fotograf iz Seattlea, koji je 1895. započeo fotografirati lokalna plemena kako bi ih sačuvao od zaborava "prije no što njihova 'izgubljena' civilizacija sasvim nestane" (McHugh 453), Curtis je stvorio jednu od najvećih kolekcija portreta indijanskih naroda u devetnaestom stoljeću. Zapečaćeni u mit imaginacije Zapada, dostojanstveni i "bezvremeni s karakterističnim pogledom u daljinu" (McHugh 453), modeli na Curtisovim antiknim sepija fotografijama prikazani su kao uspomene na rasu koja je na rubu iščeznuća i pripada povijesti.

No, paradoksalno, uništivši pravog Indijanca, ista je imaginacija stvorila njegov alegorijski pandan u bezbrojnim romanima i filmovima o Divljem zapadu i pretvorila ga u primamljiv trgovački proizvod. Prema San Juanu, rasizam kao politički i ideološki fenomen neodvojiv je od materijalnih oblika proizvodnje i podudara se s nastajanjem sustava zasnovanog na "vrijednosti razmjene: proizvodnji, kruženju i potrošnji drugog pretvorenog u robu" $(11,13)$. Zaista, u suvremenoj američkoj kulturi Indijanci su postali svakidašnjom metom masovne potrošnje i komercijalnog folklora. "Artefaktivni Indijanac", kako ga naziva Owens (2001: 19), može se pronaći posvuda - od maskota sportskih klubova, zaštitnih znakova vojne i automobilske industrije, na naljepnicama prehrambenih i duhanskih proizvoda, a u novije vrijeme i vezano uz zdravu hranu i pokrete za zaštitu okoliša (cf. Hoxie 404). "Ersatz Indijanci inspirirali su hipije, dizajnerske linije Ralpha Laurena i izviđačke skupine", primjećuje Dorris, no pravi su Indijanci rijetko imali korist od stvaranja tih imaginarnih klišeja “čija prepoznatljivost nadmašuje Mickeyja Mousea, Coca-Colu i Djeda Božićnjaka zajedno" (99). I u popularnoj kulturi dvadeset prvog stoljeća opredmećenje i eksploatacija američkih Indijanaca i njihovih kultura još uvijek su na djelu. U eri koju Luna naziva 
"Mcindijanska", indijanske su kulture postale duhovni fast food za zapadne potrošače, zapakirane i prodavane na veliko bez poštovanja prema njihovim svetim aspektima i tradicionalnim vrijednostima (cf. Blocker 24, Martin/ Atlatl 96). Jednim potezom miša suvremeni potrošač kulturni turist može uplatiti mjesta na skupim radionicama lažnih duhovnjaka gdje se oponašaju indijanske ceremonije, licitirati na hvatače snova, ceremonijalne lule, perjanice i šamanske torbice, pa i "zadobiti" indijanski identitet putem nekog od komercijalnih DNA testova. Naravno, lik Indijanca koji samo što nije iščeznuo još uvijek je tu, reproduciran na bezbrojnim kopčama za remenje i suvenirima s turističkih štandova ili, još ironičnije, na ulaznim natpisima staračkih domova (cf. Durland).

Odbivši biti dijelom tog popularnog dekora, u svojoj instalaciji ironično nazvanoj Kraj slabašnoga, Luna se satirički našalio s Fraserovim djelom, oponašajući stav njegova iscrpljenog ratnika. 


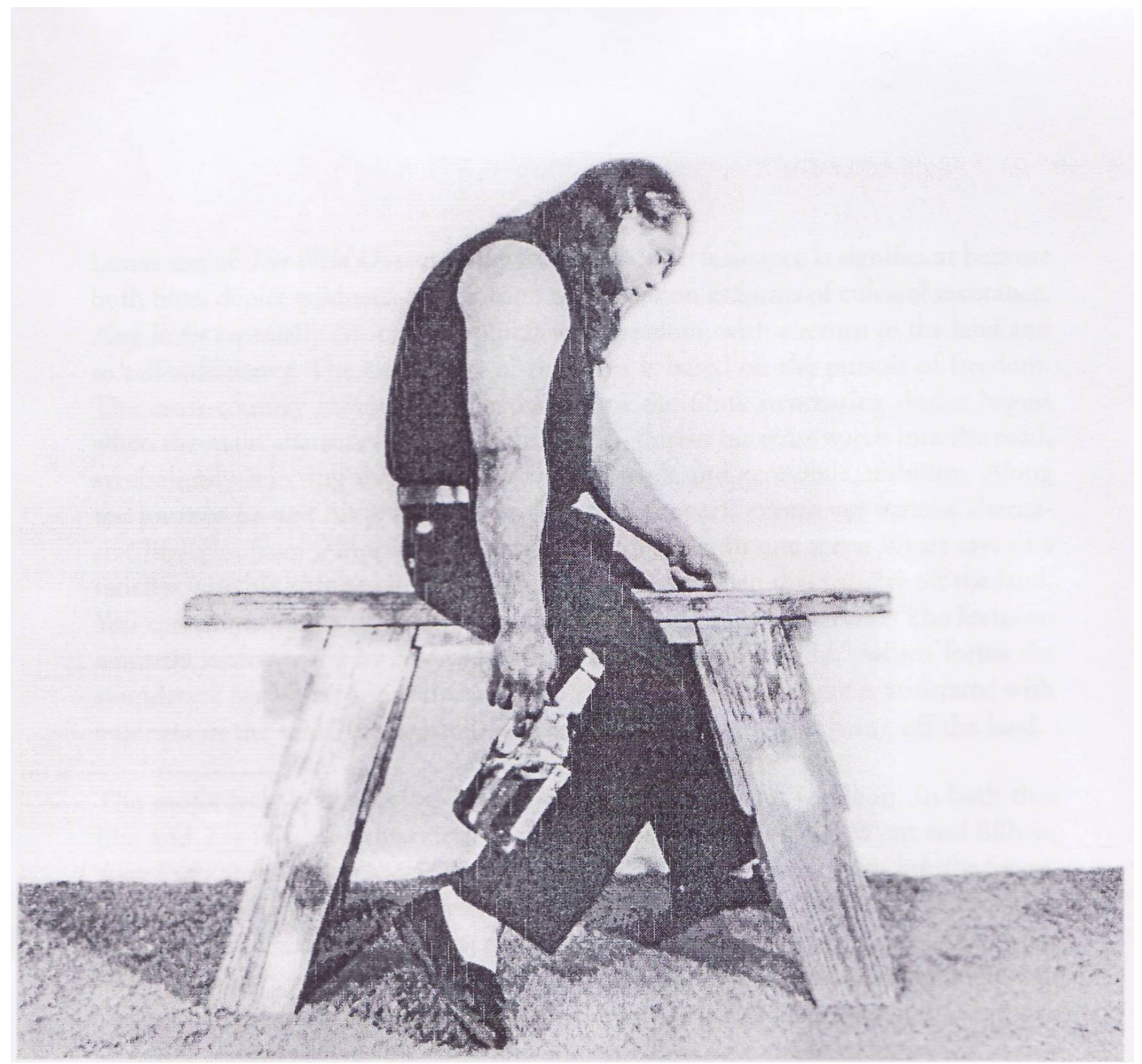

Figure 2: James Luna: The End of the Frail - 1990/91. (Luna, 2001:26)

No, umjesto konja, Luna jaše "jarca" za piljenje drva i drži bocu alkoholnog pića u ruci umjesto koplja. U suvremenoj odjeći, hineći beživotnost i umor, Indijanac dvadeset prvog stoljeća ne samo što afirmira svoju živuću prisutnost ovdje i sada već se i ruga mitu koji ga zamrzava u slike i rezbarije prošlosti. Stotinu godina kasnije "izumirući divljak" očigledno još nije nestao. On je još uvijek tu i iskače iz kolonijalnog okvira u zbilju sadašnjosti, narušavajući imaginaciju koja ga već stoljećima zatvara u mit i prošlost. Za Lunu Fraserova je skulptura dio iste one povijesne imaginacije iskrivljene željom za poetičnom autentičnošću koja je stvorila i film Ples s vukovima, koji je po njemu: 
samo veličao dobre stvari. Nije niti jednog Indijanca prikazao kao ludog ili uznemirenog. Niti jednog nije prikazao kako plače... Mi smo još uvijek svi prekrasni, stoični i zgodni. Pogledate film i onda izađete iz kina i vidite pretilu, bubuljičavu, siromašnu, neobrazovanu osobu - je li to onaj pravi Indijanac kojeg želite vidjeti? (Blocker 22)

U tom smislu, boca u Luninoj ruci nije samo komentar o toksičnosti kolonijalizma, čija ostavština alkoholizma, dijabetesa i društvene apatije još uvijek potresa indijansku Ameriku. To je ujedno još jedno sredstvo dekonstrukcije percepcije drugog jer, za razliku od koplja, vrh boce gleda prema gore, ističući samosvjesno izrugivanje onoga koji ju drži, činjenicu da on samo pozira.

Prema Owensu, autostereotipizacija može biti efektna strategija subverzije. Kako bi bio prepoznat i viđen iz centra, "Indijanac se mora povinovati identitetu nametnutom izvana" (Owens, 1998: 13) i “pozirati kao apsolutni lažnjak, fabricirani 'Indijanac'“ (2001: 17). Potvrđujući to, kao i tezu Linde Hutcheon da se mitovi, konvencije i slike ne mogu izbjeći (2002: 51; 1992: 48), Luna je izvršio obrat prikazivačke konvencije njezinim prisvajanjem i umnožavanjem. Zakoračivši u mit, oponašajući dominantni stereotip o sebi samom, on, Bahtinovim riječima, podcrtava "tuđe riječi" i "odjeke tuđih iskaza" (1986: 88) i postiže ono što Bhabha opisuje kao ponavljanje, premještanje i prevođenje "strategije prikazivačkog autoriteta" (1995: 207). Hibridnost predstavlja "ambivalentan 'obrat' diskriminiranog subjekta”, tumači Bhabha; hibridni predmet zadržava privid autoritarnog simbola, ali "prevrednuje njegovu prisutnost" (2002: 115) ponavljanjem efekata diskriminirajućeg identiteta (2002: 112) "koje uzrokuje to da se dominantni diskurs cijepa duž vlastite osi reprezentativnosti, autoriteta" (2002: 114):

...poput kamuflaže, mimikrija nije usklađivanje ili potiskivanje različitosti, već oblik nalikovanja koji se razlikuje od prisutnosti ili ju čuva prikazavši ju djelomično, metonimijski. Njezina prijetnja... dolazi od ogromne i strateške proizvodnje konfliktnih, fantastičnih, diskriminirajućih "efekata identiteta"... (2002: 90)

Mimikrija dakle postavlja pitanja autoriteta i "autorizacije kolonijalnih prikaza" (Bhabha, 2002: 90), prevrednuje uvriježene stavove o "prvenstvu rase, pisanja, povijesti" i "reartikulira prisutnost u 
smislu njezine 'drugosti', onoga što se poriče” (Bhabha, 2002: 91). Dehistoricirajući i razvlašćujući simbole svog prototipa, Kraj slabašnoga postiže upravo taj efekt.

Po mnogo čemu Luna se dobro uklapa u Vizenorov koncept "Postindijanca". Prema Vizenoru, "Postindijanac je odsustvo izmišljotine i kraj prikaza", "slom one neuhvatljive melankolije dominacije" (1994: 11). Suvremeni indijanski pisci i umjetnici, koji potkopavaju dominantne simulacije, stvaraju novu plemensku prisutnost u pripovijestima, svoje vlastite "revizije" i "simulacije" (1994: 12). Ti "postindijanski ratnici”, kako ih naziva (cf. 1994: 12), zauzimaju položaj koji on označava kao survivance ${ }^{2]}$ (1994: 169); oni ostaju "plemenski" (cf. Krupat 228) istodobno djelujući u suvremenoj kulturi. Luna, koji sam sebe naziva "suvremeni tradicionalist" (Fletcher), koristi satiru kako bi propitao i dekonstruirao fiksna značenja, "slike i prisutnosti autoriteta" (cf. Bhabha, 2002: 114) na način koji priziva i Vizenorovu teoriju varalice (izv. trickster). Kao jedan od najpopularnijih likova u indijanskoj pripovjednoj tradiciji, varalica predstavlja komičnu hiperboličnu inačicu čovjeka koja se, čineći nepodopštine, opire svim vrlinama i vrijednostima - obiteljskim, kulturnim i društvenim (Ramsey 27). Kroz svoj negativan primjer varalica određuje granice dopustivog "koje ne smijemo prijeći” (Ballinger, 1992: 25), ali ima i sposobnost preobrazbe same zbilje, rastvaranja granica i otvaranja novih vidokruga i mogućnosti (cf. Ramsey 27). Za Vizenora varalica nije "stvarna osoba ili biće u ontološkom smislu", već "komični holotrop" (1993: 187) "u jezičnoj igri" (1988: x, 1991: 80), "semiotički znak" (1990: 192, 284) koji svojom fleksibilnošću te anarhičnom kreativnom energijom oslobađa i stvara nove mogućnosti društvenog diskursa, stavlja na kušnju dominantne ideje, zakone i konvencije (1988: ix; 1990: 278; Blair 76, 77). Kao "društvena sankcija koja nudi novi pogled na stvari” (Bowers 140), komični likovi poput varalice imaju ključnu ulogu pri preobrazbi i revitalizaciji kulture, a često se pojavljuju upravo u situacijama koje prijete raspadom kulturnih vrijednosti (Smith 3, 7-8). Slično Bhabhinom trećem prostoru, koji razjedinjuje i olabavljuje fiksnost kulturnih simbola (1995: 206-209), varaličina sposobnost da prijeđe i rastoči granice može izazvati obrat zakona, vlada i društvenih konvencija, razvrgnuti uvjerenja, ideje i ideologije. Diskurs varalice, tumači Klinkovitz, može "razotkriti hibridnu narav svake kulture, ambivalentnost u izvoru svakog nametanja koja omogućuje njezinu subverziju" (349). Kao takav, varalica predstavlja i efektno oruđe antikolonijalne borbe (cf. Owens, 1998: 6). 
U Bilješkama o mojoj umjetnosti (izv. Notes on My Art Work \#674) Luna je izrazio svoj afinitet prema komičnom modusu. Za njega humor je "prvi korak prema regeneraciji":

Ja nisam iscjelitelj, ali mogu se smatrati klovnom. (nav. u "James Luna: Petroglyphs in Motion")

Moja sklonost prema humoru u onome što radim potiče iz indijanske kulture, gdje humor može biti oblik znanja, kritičke misli ili možda samo sredstvo za ublažavanje boli. Mislim da mi Indijanci živimo u svijetu koji je pun ironije i želim o tome govoriti u svojim djelima.... (Durland)

Poput Lune, mnogi indijanski teoretičari naglašavaju važnost humora u indijanskim kulturama, njegov potencijal da destabilizira metapripovijesti "osvajanja i asimiliacije" (Allen, nav. u Lincoln 7) i njegovu povezanost s povijesnim pamćenjem (cf. Peterson 36). "Humor je osnovno sredstvo pomirbe tradicije postojanja, zajedništva i slavljenja s okrutnim činjenicama rasnog razaranja", tumači Allen (159). Slično, Vine Deloria Jr. ističe terapijsku moć lakrdijaštva u indijanskim tradicijama (146-167) i vidi humor kao glavno sredstvo opstanka suvremenih Indijanaca:

Za Indijance je uvijek bilo veliko razočaranje to što takozvani stručnjaci za indijanska pitanja nikad nisu spomenuli humorističnu stranu indijanskog života. Naprotiv, američka mitologija neprestano vrti onu sliku smrtno ozbiljnog neartikuliranog crvenokošca. (Deloria 146)

Smijeh obujmljuje granice duše. Kroz humor život se redefinira i prihvaća... (Deloria 146)

Kad se narod može smijati samom sebi i drugima i držati na okupu sve aspekte života, a da ih nitko ne može odvesti u krajnost, tada, čini mi se, narod može preživjeti. (Deloria 167)

Luna obilno koristi humor u svojim instalacijama. U djelu Artefakt (izv. The Artefact Piece), prvi put izvedenom 1987. u Muzeju čovjeka u San Diegu, a potom i 1990. na Paradi desetljeća u New Yorku, Luna je samog sebe izložio kao muzejski artefakt u odjeljku posvećenom Kumeyaay Indijancima koji su nekoć živjeli u okrugu San Diega. Omotan samo komadom tkanine oko bokova, nekoliko je dana nepomično ležao u vitrini okružen natpisima sa svojim imenom i pojašnjenjima vezanim uz "ožiljke na njegovu tijelu" - posljedicama "prekomjernog uživanja alkohola" $i$ "uličnih borbi". Pored njega tu su još bili i predmeti "tipični za suvremenog Indijanca" (Fletcher) - osobni 
dokumenti poput Luninih brakorazvodnih spisa te memorabilije - albumi Rolling Stonesa i Jimija Hendrixa, kasete, znakovlje aktivističkih pokreta iz šezdesetih, "pozamašna kolekcija cipela", kao i neki ceremonijalni predmeti s Luiseno rezervata (Fletcher, Golar 29). Poput Kraja slabašnoga, i ova je instalacija potaknula pitanja nepostojanja i nevidljivosti pravih Indijanaca u dominantnoj kulturi. U maniri varalice, koji je tradicionalno poznat i kao “imitator” (Lincoln 136, Klinkowitz 349), Luna je još jednom posegnuo za autoetnografskim izričajem, humorom i kritičkom parodijom, kako bi propitao konvencije opredmećenja i simbolizacije američkih Indijanaca kao izumrlih naroda izdvojenih iz službenih pripovijesti o povijesti, identitetu i kulturi:

"Dugo sam promatrao prikaze naših ljudi u muzejima”, objašnjava Luna, "i oni su svi pripadali prošlosti. Bili su jednostrani. Bili smo jednostavno predmeti među kostima, kosti među predmetima,

a potom popisani i zapečaćeni s datumom. U tom sistemu zaista niste mogli govoriti o radosti, inteligenciji, humoru, niti o bilo čemu drugome što znam da krasi naše ljude”. (Fletcher)

Tijekom godina, discipline poput antropologije, arheologije i etnologije postale su glavnom metom indijanske kritike.

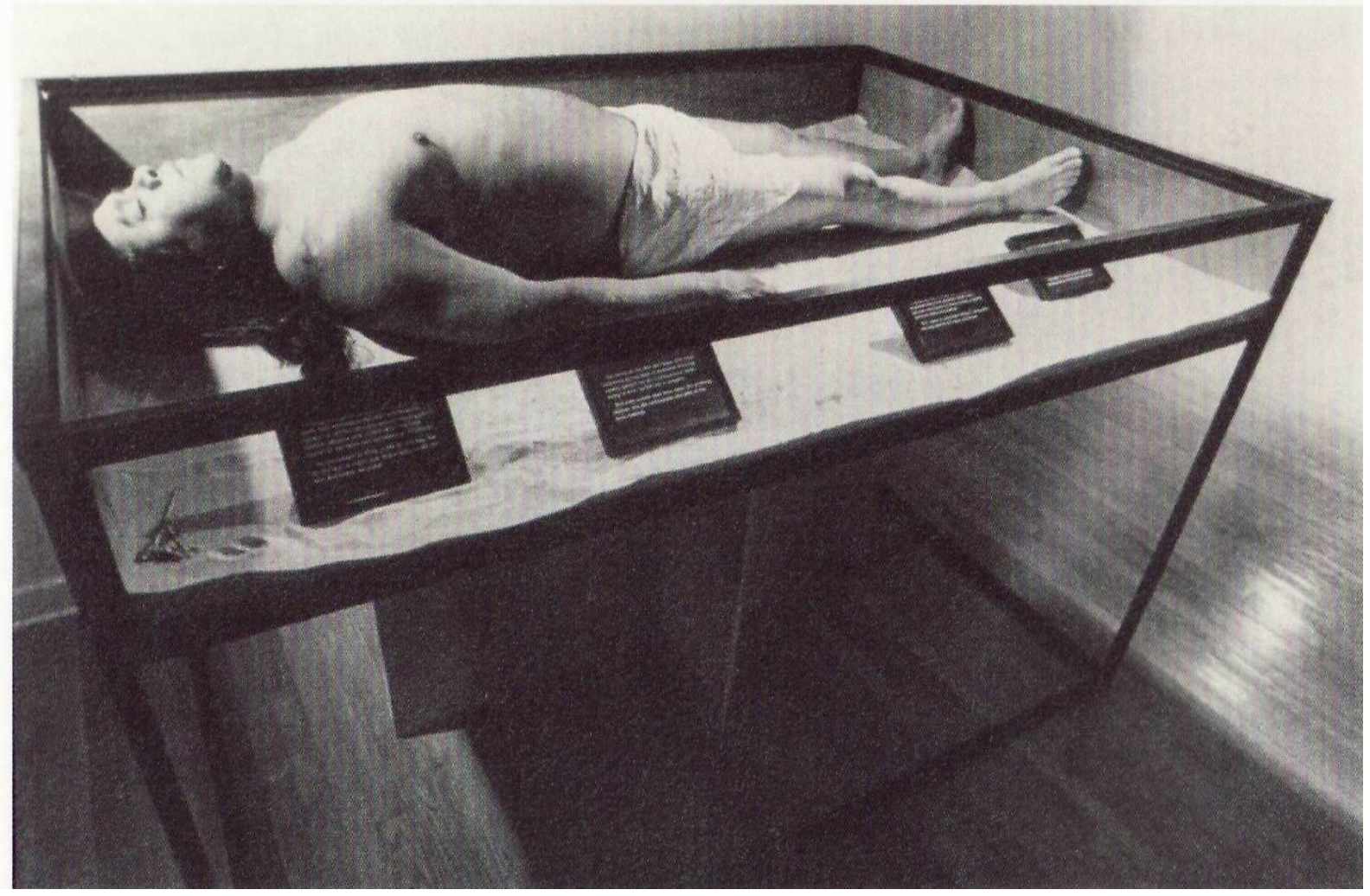


Figure 3: James Luna: The Artifact Piece - 1990. (Luna, 2005:6)

Prema Deloriji, zbog svog neutaživog apetita za osvajanjem drugih kultura, za eksperimentiranjem, sakupljanjem i dokumentiranjem drugog, antropologija je stvorila "konceptualni zatvor u koji je bacila Indijance" (93), produbljujući njihov položaj drugog pogrešnom interpretacijom i erozijom njihovih kultura:

... ogromna masa beskorisnog znanja koju su proizveli antropolozi kako bi prave Indijance zarobili u mrežu teorija u velikoj je mjeri pridonijela današnjoj nevidljivosti Indijanaca. (Deloria 81)

Indijanci su ... sigurni da je Kolumbo na svojim brodovima imao antropologe kada je došao u Novi svijet. Kako bi inače stvorio toliko pogrešnih sudova o tome gdje se nalazio? (Deloria 79)

Sasvim suprotno svojoj misiji zaštite i očuvanja kulturnog nasljeđa, etnologija je također postala samo još jedan alat za diseminaciju indijanske nevidljivosti. Danas za mnoge Indijance muzeji ne simboliziraju ništa drugo do očitovanja institucionalizirane pljačke i devastacije njihovih kultura. Sve do donošenja zakona poznatog kao NAGPRA ${ }^{[3]}$ 1990. indijanski narodi nisu bili u mogućnosti vratiti kulturne predmete i ljudske ostatke svojih predaka, nerijetko žrtava masovnih pogubljenja poput onih kod rječica Sand Creek (1864) i Wounded Knee (1890). Neposredno nakon tih događaja osobne su stvari, ceremonijalni predmeti i dijelovi tijela stradalnika masovno odnošeni s mjesta nesreće, a potom na rastućem tržištu artefakata s kraja devetnaestog stoljeća preprodavani znanstvenicima i privatnim kolekcionarima, sveučilišnim, vladinim i etnološkim institucijama koje su in potom pretvarale u izložbene primjerke i javno prikazivale. Od donošenja NAGPRE ljudski ostaci više od 38 tisuća pojedinaca ${ }^{4]}$, gotovo milijun pogrebnih predmeta i više od četiri tisuće svetih predmeta vraćeni su indijanskim plemenima (cf. U.S. Department, "Reclaiming Identity"). Mi nemamo obvezu ni prema kome osim prema sebi samima kada je u pitanju očuvanje indijanske kulture, kažu suvremeni indijanski znanstvenici Elizabeth Cook-Lynn i Philip Deloria (cf. Littlefield 96), odbijajući prihvatiti etnografske interpretacije i rasprodaju svoje kulture. Slično, ističući da "tkogod kontrolira nečije određenje, kontrolira i njegovo poimanje sebe samog", Paula Gunn Allen ukazuje kako je osnovni zadatak suvremenih indijanskih pisaca i umjetnika ponovno prisvojiti sebe same i "istrgnuti se od Hollywooda, od antropologije" (nav. u Bataille 399). 
Skrenuvši pozornost na sebe kao artefakt, Luna je jasno razotkrio vezu između institucija znanja Zapada, imperijalizma i kulture spektakla, činjenicu da gledateljeva konzumacija artefaktnog d rugog odražava i održava društvene odnose moći.

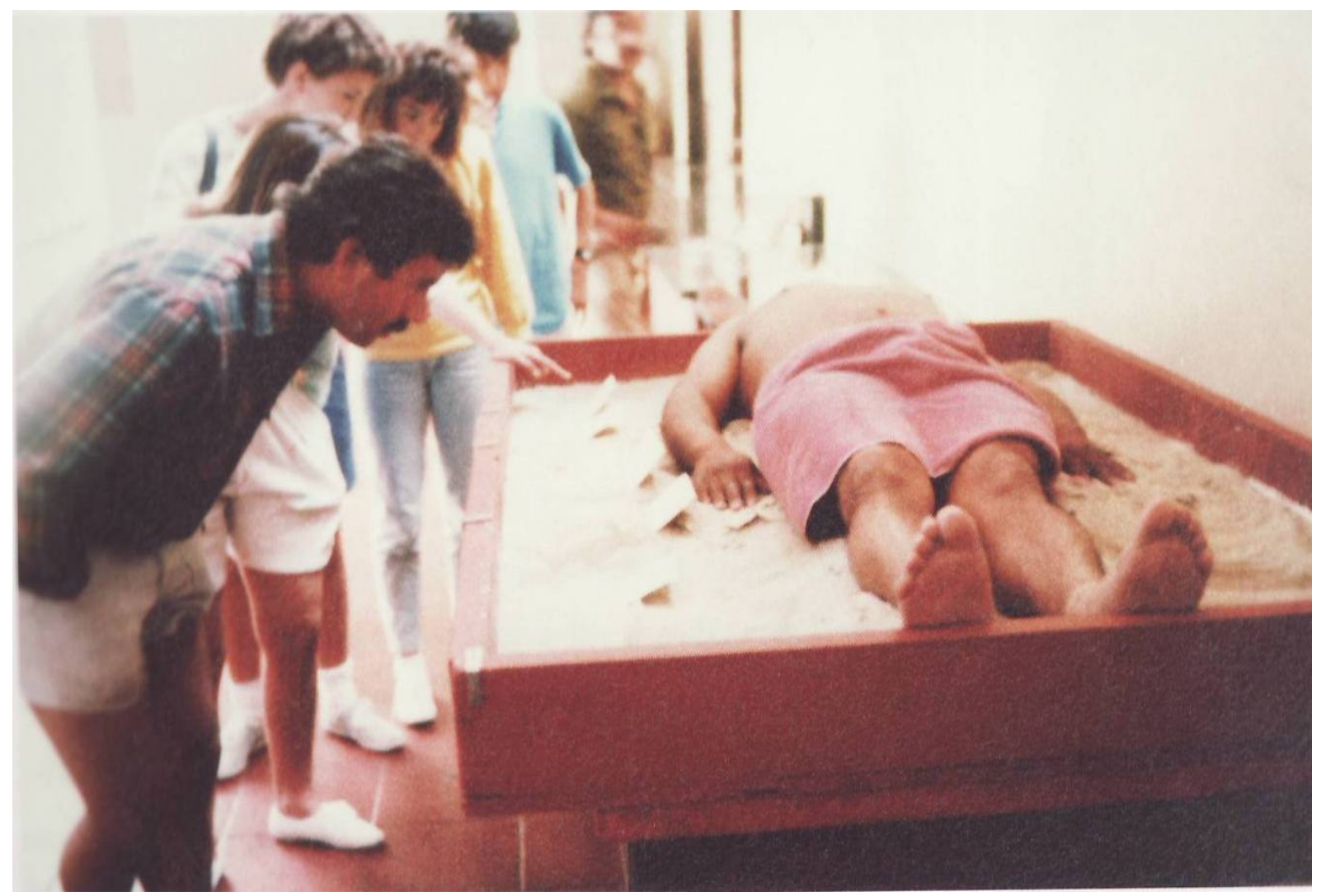

Figure 4: James Luna: The Articaft Piece - 1987. (Luna, 2005:15)

Ukazavši na "okliznuće između identiteta i različitosti" (Bhabha, 2002: 90), tako što je muzejskoj publici izložio samog sebe, živućeg suvremenog Indijanca, Luna je osporio formativnu snagu etnografskog nadzora. On je dakle još jednom poremetio "metonimije prisutnosti" (Bhabha, 2002: 90), i prisvojio subjektivnost nečujnog drugog. Kako bi tema bila komična, ona mora biti približena, tumači Bahtin. Smijeh uništava svaku distancu; on ometa i djeluje "u zoni maksimalnog približavanja" (1989: 455), a likove razotkriva kao subjekte njihova vlastitog, a ne oficijelnog diskursa (Bauer 674, 680). Slično, i hibridnost ima destabilizirajući efekt tako što izvlači na vidjelo "nužnu deformaciju i premještanje svih položaja diskriminacije i dominacije" te upravlja "pogled diskriminiranog nazad prema oku moći” (Bhabha, 2002: 112). Lunina je performativna poruka proizvela upravo takav efekt. Mnogi posjetitelji izložbe bili su zbunjeni, pa i šokirani, kad su shvatili da gledaju u izloženog živućeg Indijanca koji im uzvraća pogled. Anegdota s instalacije u San Diegu kaže kako je, dok je ležao u staklenoj vitrini, Luna bio svjedokom razgovora euro-američkog 
para koji ga je promatrao. Proučavajući tijelo, žena se obratila suprugu: "Dragi, mislim da je on živ", a suprug je uzvratio riječima: "Ne budi smiješna; ne stavljaju ih žive u muzeje" (Durham 424). Ipak, čovjek u staklenoj vitrini bio je sve samo ne mrtav. "Jedini dobar Indijanac je mrtav Indijanac", ponavljali su general Sheridan i njegovi bezbrojni holivudski klonovi. No, on je još uvijek tu postindijanski varalica koji simulira iščeznuće, ali istodobno diše, smije se i uzvraća pogled, otima svoj identitet od kolonijalnog centra u centru samom i dokazuje da "jednom kad je Indijanac slobodan sam zamisliti svoju sudbinu ili fabulu ... osnažiti se kroz smijeh prema drugima i prema sebi samom - on izmiče gotičkoj dijalektici koja zahtijeva njegovu propast i njegov nestanak" (Owens, 1998: 92).

\section{Bibliografija}

Allen, Paula Gunn. The Sacred Hoop: Recovering the Feminine in American Indian Traditions. Boston: Beacon, 1986. Print.

Bahtin, Mihail. O romanu. Trans. Aleksandar Badnjarević. Beograd: Nolit, 1989. Print.

Bakhtin, Mikhail. Speech Genres and Other Late Essays. Ed. Caryl Emerson and Michael Holquist. Trans. Vern W. McGee. Austin: University of Texas Press, 1986. Print.

Ballinger, Franchot. "Coyote He/She Was Going There: Sex and Gender in Native American Trickster Stories." Studies in American Indian Literatures. 2000. 15-43. Print.

Bataille, Gretchen, ed. Native American Literary Representations: First Encounters, Distorted Images, and Literary Appropriations. Lincoln and London: University of Nebraska Press, 2001. Print.

Baudrillard, Jean. Simulations. Trans. Paul Foss et al. New York: Semiotext(e), 1983. Print. Bauer, Dale. "Gender in Bakhtin's Carnival." 1988. Ed. Robyn R. Warhol and Diane Price Herndl. New Brunswick: Rutgers University Press, 1993. 671-690. Print.

Bevis, William. "Native American Novels: Homing In." Recovering the Word: Essays on Native American Literature. Ed. Brian Swann and Arnold Krupat. Berkeley: U of California P, 1987. 580-620. Print. 
Bhabha, Homi. "Cultural Diversity and Cultural Differences." The Post-Colonial Studies Reader. Ed. Ashcroft, Bill, Gareth Griffiths and Helen Tiffin. London and New York: Routledge, 1995. 206-213. Print.

Bhabba, Homi. The Location of Culture. 1994. London and New York: Routledge, 2002. Print. Blair, Elizabeth. "Text as Trickster: Postmodern Language Games in Gerald Vizenor's Bearheart." MELUS 20. 1995. 75-90. Print.

Blocker, Jane. "Failures of Self-Seeing: James Luna Remembers Dino." A Journal of Performance and Art. 2001.: 18-32. Print.

Bowers, Sharon Manybeads. "Louise Erdrich as Nanapush." New Perspectives on Women and Comedy. Ed. Regina Barreca. Philadelphia: Gordon and Breach, 1992. 135-43. Print.

Churchill, Ward. Fantasies of the Master Race: Literature, Cinema and the Colonization of American Indians. San Francisco: City Lights Books, 1998. Print.

Deloria, Vine. Custer Died for Your Sins: An Indian Manifesto. Norman: University of Oklahoma Press, 1988. Print.

Dorris, Michael. "Indians on the Shelf." The American Indian and the Problem of History. Ed. Calvin Martin. New York: Oxford University Press, 1987. 98-106. Print.

Durham, Jimmie. "Cowboys and...: Notes on Art, Literature, and American Indians in the Modern American Mind." The State of Native America: Genocide, Colonization, and Resistance. Ed. Annette M. Jaimes. Boston: South End P, 1992. 423-439. Print.

Durland, Steven. "Call Me in '93: An Interview with James Luna." The Citizen Artist: 20 Years of Art in the Public Arena: An Anthology from High Performance Magazine 1978-1998. Ed. Steven Durland and Linda Frye Burnham. Web. 8 Aug. 2010 http://www.communityarts.net/readingroom/archivefiles/2002/09/call_me_in_93_a.php>. Fletcher, Kenneth R. “James Luna” Smithsonian Magazine Apr. 2008. Web. 8 Aug. 2010 http://www.smithsonianmag.com/arts-culture/atm-qa-james-luna.html>.

Fraser, James Earle. The End of the Trail. 1894. City Clerk's Office, Waupun, Wisconsin. 
Reproducirano u "Failures of Self-Seeing: James Luna Remembers Dino." By Jane Blocker. Performing Arts Journal: A Journal of Performance and Art. 23.1 (2001): 18-32. Print.

Golar, Staci. "Shape Shifters: Performance Art and Humor as a Tool." Native People's Magazine. 2009. 28-33. Print.

Hall, Stuart, and Paul Du Gay. Questions of Cultural Identity. 1996. London: Sage Publications, 2000. Print.

hooks, bell. Black Looks: Race and Representation. Boston: South End Press, 1992. Print.

Horsman, Reginald. Race and Manifest Destiny: The Origins of American Racial Anglo-Saxonism. Cambridge: Harvard UP, 1981. Print.

Hoxie, Frederick E., ed. Encyclopedia of North American Indians. New York: Houghton Miflin Company, 1996. Print.

Hutcheon, Linda. A Poetics of Postmodernism: History, Theory, Fiction. 1988. New York and London: Routledge, 1992. Print.

Hutcheon, Linda. The Politics of Postmodernism. 2nd ed. London and New York: Routledge, 2002. Print.

Jacobs, Connie A. The Novels of Louise Erdrich: Stories of Her People. New York: Peter Lang, 2001. Print.

“James Luna: Petroglyphs in Motion.” N.p. Web. 8 Aug. 2010

http://www.scu.edu/desaisset/exhibits/luna.html>.

JanMohamed, Abdul. "The Economy of Manichean Allegory." The Post-Colonial Studies Reader. Ed. Ashcroft, Bill, Gareth Griffiths and Helen Tiffin. London and New York: Routledge, 1995. 18-24. Print.

Karrer, Wolfgang, and Harmut Lutz, eds. Minority Literatures in North America: Contemporary Perspectives. Frankfurt: Peter Lang, 1990. Print.

Klinkowitz, Jerome. "Fiction: The 1960 to the Present." American Literary Scholarship 98.1 (1998): 337-360. Print. 
Krupat, Arnold. "Nationalism, Indigenism, Cosmopolitanism: Three Critical Positions on Native American Literatures." Mirror Writing: (Re)Constructions of Native American Identity. Ed. Thomas Claviez and Maria Moss. Berlin: Galda und Wilch Verlag, 2000. 213-237. Print.

Lee, Robert. Loosening the Seams: Interpretations of Gerald Vizenor. Bowling Green: Bowling Green State University Press, 2000. Print.

Lincoln, Kenneth. Native American Renaissance. Berkeley: University of California Press, 1983. Print.

Lippard, Lucy. Mixed Blessings. New York: INTAR Gallery, 1989. Print.

Littlefield, Daniel F. "American Indians, American Scholars, and the American Literary Canon." American Studies 1992. 95-111. Print.

Loomba, Ania. Colonialism/Postcolonialism. London and New York: Routledge, 1998. Print. Luna, James. The End of the Frail. 1990-91. Mixed Media Installation from AA Meeting/ Art History. Photo by Richard Lou. Reproducirano u "Failures of Self-Seeing: James Luna Remembers Dino." By Jane Blocker. Performing Arts Journal: A Journal of Performance and Art. 23.1. (2001): 18-32. Print.

Luna, James. The Artifact Piece. Reproducirano u James Luna - Emendatio. 1987. By Elisabeth Kennedy Gische, ed. Washington D. C.: National Museum of the American Indian, 2005. 15. Print. Luna, James. The Artifact Piece. Reproducirano u James Luna - Emendatio. 1990. By Elisabeth Kennedy Gische, ed. Washington D. C.: National Museum of the American Indian, 2005. Print. Atlatl, Martin, Linda R. “James Luna.” Native People’s Magazine 1997. 96-96. Print.

Matchie, Thomas. "Writing about Native Americans: the Native and Non-Native Critic/Author." The Midwest Quarterly 42.3 (2001): 320-33. Web. 9 June 2003. http://www.radford.edu/itw/infomark>. McClintock, Anne. "The Angel of Progress: Pitfalls of the Term 'Post-colonialism'." Colonial Discourse and Post-Colonial Theory: A Reader. Ed. Williams, Patrick and Laura Chrisman. New York: Columbia UP, 1994. 291-304. Print. 
McHugh, Kathleen. "Profane Illuminations: History and Collaboration in James Luna and Isaac Artenstein's The History of the Luiseno People." Biography: An Interdisciplinary Quarterly, 2008. 429-460. Print.

Owens, Louis. "As If an Indian Were Really an Indian: Native American Voices and Postcolonial Theory." Native American Literary Representations: First Encounters, Distorted Images, and Literary Appropriations. Ed. Gretchen Bataille. Lincoln and London: U of Nebraska P, 2001. 11-26. Print.

Owens, Louis. Mixedblood Messages: Literature, Film, Family, Place. Norman: University of Oklahoma Press, 1998. Print.

Pease, Donald E. "New Perspectives on U.S. Culture and Imperialism." Cultures of United States Imperialism. Ed. Amy Kaplan and Donald E. Pease. Durham and London: Duke UP, 1993. 22-41. Print. 
[1] Vizenor ovaj termin namjerno označava malim slovom.

[2] Vizenorov neologizam nastao spajanjem riječi otpor i opstanak (izv. resistance and survival) (cf. Lee 79).

[3] Zakon o zaštiti i repatrijaciji indijanskih posmrtnih ostataka (izv. Native American Graves Protection and Repatriation Act).

[4] Prestižni Smithsonian muzej primjerice bio je u posjedu kolekcije od gotovo 17.000 indijanskih posmrtnih ostataka.

\section{(c) (i) (3)}

Creative Commons Attribution-NonCommercial-NoDerivatives 4.0 International License 